\title{
Infección avanzada por virus de inmunodeficiencia humana: el tratamiento antiretroviral combinado se asoció a menor morbimortalidad
}

Declining morbidity and mortality among patients with advanced human immunodeficiency virus infection.

Palella FJ, Delaney KM, Moorman AC, et al. (HIV Outpatient Study Investigators) NEJM 1998;338:853-60.

\section{Objetivo}

Evaluar la evolución de la mortalidad y la morbilidad asociadas a la infección avanzada por virus de inmunodeficiencia humana (VIH) en una cohorte de pacientes, y determinar su correlación con el régímen terapéutico.

\section{Diseño}

Estudio observacional en una cohorte de pacientes durante 42 meses (Ene 1994-Jun 1997) a partir de una base de datos multicéntrica.

\section{Lugar}

Estudio multicéntrico realizado en nueve centros de Estados Unidos.

\section{Pacientes}

Pacientes con al menos un recuento de células CD4+ de menos de 100 por mm3 ( $n=1255)$.

El $80 \%$ tenía entre 30 y 49 años, el $20 \%$ era de raza negra, el $9 \%$ hispánicos y el $12 \%$ mujeres. El $65 \%$ de los pacientes refirió actividad sexual con personas del mismo sexo y el $14 \%$ refirió utilización de drogas intravenosas.

\section{Medición de resultados principales}

Análisis cuatrimestral determinando la mortalidad y la morbilidad (infecciones oportunistas en general; y retinitis por citomegalovirus, neumonía por Pneumocystis carinii e infección por M. avium en particular) en función del tratamiento antiretroviral (sin tratamiento, monoterapia, combinación sin inhibidor de proteasa y combinación con inhibidor de proteasa), del recuento de CD4 en la visita inicial y del tipo de cobertura de salud.

\section{Resultados Principales}

Se observó un cambio significativo en la proporción de pacientes que recibieron tratamiento antiretroviral ( $72 \%$ en 1994 a $95 \%$ en 1997) y en los pacientes con tratamiento de combinación con un inhibidor de proteasa ( $2 \%$ en 1995 a $82 \%$ en 1997$)$.

La mortalidad se mantuvo constante en 1994 y 1995 pero se redujo de 29.4/100 pacientes-año en 1995 a 8.8 por 100 pacientes-año en 1997. El descenso de la mortalidad se comprobó para todas las variantes demográficas y demostró una correlación con la intensidad del tratamiento antiretroviral indicado. Los promedios de mortalidad fueron mayores para los pacientes con cobertura pública de salud, pero este hallazgo pareció relacionarse con el patrón de tratamiento antiretroviral prescripto. La incidencia de infecciones definidoras de SIDA disminuyó de 50/100 pacientes-año en 1994 a 13.3/100 pacientes-año en 1997. Este descenso se comprobó en particular para las infecciones más significativas estudiadas.

Los valores de carga viral obtenidos presentaron una correlación inversa con la intensidad del tratamiento.

\section{Conclusiones}

Los datos demuestran una reducción muy significativa de la mortalidad y la morbilidad asociadas a la infección por VIH en pacientes con enfermedad avanzada. Esta reducción está claramente ligada al uso creciente de tratamiento antiretroviral combinado, y en particular con inhibidores de proteasa. Se analizó un período en el cuál los patrones de prescripción de tratamiento profiláctico de infecciones oportunistas no varió demasiado. Esta reducción pudo ser demostrada independientemente de las características demográficas de la población.

\section{COMENTARIO}

Con las limitaciones conocidas de todo estudio retrospectivo y observacional, este trabajo presenta varias características interesantes. La idea general de la reducción de la mortalidad vinculada al tratamiento antiretroviral de alta eficacia existía desde hacía algo más de un año. Hasta este momento los datos provenían o bien de poblaciones participantes en estudios clínicos (que tienen sesgos conocidos y muchas veces son difíciles de aplicar extensamente por su variable validez externa), o de fuentes oficiales (que sólo contenían datos crudos con pocas posibilidades de análisis adicionales). La evaluación sobre una cohorte prospectiva permite obtener precisiones sobre los factores asociados con dicha reducción en un escenario más cercano a la "vida real". Por otra parte las características demográficas de la población no parecen diferir demasiado de los datos generales para la población de Estados Unidos. La población argentina afectada por la infección por VIH presenta características ligeramente diferentes, pero sería esperable encontrar una reducción similar en la morbimortalidad en la medida que el sistema de registro estadístico de los datos demográficos y clínicos de los pacientes fueran optimizados. Por otra parte, el estudio demuestra dos aspectos adicionales muy interesantes: 1) la posibilidad de estudiar cohortes multicéntricas en infección por HIV a partir de bases de datos comunes, y 2) la confirmación de que el tratamiento antiretroviral en estadios avanzados de infección por HIV, lejos de ser un aspecto cuestionable, es una práctica de tras- cendental importancia capaz de producir un gran impacto en la sobrevida y la calidad de vida de nuestros pacientes. A pesar de los altos costos individuales y sociales, parece estar cada vez más establecido el importante beneficio de los antiretrovirales combinados, especialmente asociados a una droga inhibidora de la proteasa.dio, esta causa representa el $75 \%$ de todas las muertes; tampoco son evaluadas los episodios agudos de consumo (binge) de grandes cantidades de alcohol que pueden contribuir a esta. También es importante evaluar los eventos coronarios y cerebrovasculares no fatales, pero el estudio no se diseñó para registrarlos. Sería interesante realizar un ensayo clínico controlado en prevención secundaria con pacientes con enfermedad coronaria, ya que por el alto riesgo basal podrían tener un importante beneficio. Otra línea de investigación posible e interesante es la sintesis de un principio activo del alcohol que conserve el efecto beneficioso sobre el corazón sin su efecto deletéreo. El alcohol posee efectos beneficiosos en aquellos sujetos que padecen enfermedad arterioesclerotica y/o mayor riesgo cardiovascular; cuando el riesgo es intermedio o bajo el beneficio es marginal, y cuando el alcohol es consumido a altas dosis su efecto es claramente perjudicial (4). No hay ninguna sociedad científica reconocida que actualmente recomiende la prescripción de alcohol, esta solamente puede ser evaluada por el medico en su consultorio en virtud al riesgo y características individuales de cada paciente.

\section{Dr.Waldo H. Belloso}

Sección Infectología. Hospital Italiano de Buenos Aires.

Referencias

1. Update: trends in AIDS incidence, deaths and prevalence. United States, 1996. MMWR 1997; 46:165-73.

2. Torres RA., Barr M. Impact of combination therapy for HIV infection on inpatient census. N Eng IJ Med. 1997; 336: 1531-2

3. Hogg RS., O'Shaughnessy MV., Gataric N., et al. Decline in deaths from AIDS due to new antiretrovirals. Lancet 1997; 349: 1294. 